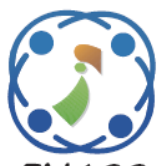

\title{
Impact of the Harmonic Pollution of Railway Locomotive on the Sound System: Experimental Measurement, Modelling and Simulating
}

\author{
Moine El Hajji ${ }^{1 *}$ \\ Hassane Mahmoudi ${ }^{1}$ \\ Moussa Labbadi ${ }^{1}$ \\ ${ }^{1}$ Power Electronics Team, Intelligent Control, Automatic and Robotic Techniques, \\ Mohammadia School of Engineers, Mohammed V University Rabat, Morocco \\ * Corresponding author's Email: moine.elhajji@ gmail.com
}

\begin{abstract}
Air pollution caused by the transport sector has become a very worrying subject. To minimize toxic gas emissions, people start to prefer rail transportation. This high demand has caused high energy consumption in the electric railway. Thus, Moroccan Railway Company was obliged to use different traction locomotives of different technologies which can generate electromagnetic interferences between systems. Reason why the study of electromagnetic pollution has become a necessity to avoid these inter-system electromagnetic disturbances by analysing the experimental measurements on the railway site and by proposing a solution which is the implementation of an active filter capable of eliminating the parasites caused during the connection of the locomotive. However, the authorization to put into operation remains a real subject of study since different parameters must be taken into account, namely the weight, the location, the size and the electromagnetic interferences (EMI) of the filter. This paper discusses the electromagnetic noise by analyzing the impact of the auxiliary power supply quality generated by electric locomotive E1250 on the sound systems when it is coupled to multi-unit Corail cars and by detailing an overview of the conversion chain located in the electric locomotive under test and the sound system installed in Corail car which keeps passengers constantly informed when approaching and arriving at a station, and gives them other indications about the train. Next, static test bench and dynamic experimental tests will be measured in order to determine the Electromagnetic Compatibility (EMC) disturbances in the Common Mode (CM) by studying the harmonics generated by the static converter that feeds the Corail cars, and analyzing their impact on all operating systems especially sound system since it is considered as a very sensitive organ to the least source of noise. In the end, the conversion system will be modeled and a proposed solution will be implemented to mitigate the electromagnetics noises.
\end{abstract}

Keywords: Railway transport, Power quality, Static converter, EMC, Harmonics pollution.

\section{Introduction}

Railway transport is considered to be one of the most efficient modes of transport from an environmental and energy point of view, particularly in terms of greenhouse gas emissions [1]. To minimize carbon emissions, the railway companies opt for the electrification of railway lines in terms of ecological and pro-environmental transport motivation $[2,3]$.

The Moroccan railway network has $64 \%$ of the electrified lines with a $3 \mathrm{kV}$ DC and $2 \times 25 \mathrm{kV}$ AC power supply. The transport activity of ONCF is divided into three different segments: passenger transport, freight and phosphate transport. According to a recent survey, passengers prefer to take railway transport often for ecological and environmental reasons $[4,5]$. As a result, there is a high demand for rolling stock reserved for travelers during peak hours and holiday periods, which can have a negative impact on the environment [6]. This strong demand for locomotives, self-propelled trains, Corail passenger carriage is pushing the railway office to use old locomotives to fill the lack of availability. However, due to the diversity of the railway fleet available, the quality of the network and the limitation of harmonic electrical pollution 
has become a commitment and a priority to avoid interference between railway equipment.

Various reports of dysfunction of the sound system have been located when connecting an old type of locomotive named E1250 which is still in service since there is a high demand for availability of railway equipment during the specific periods. The problem was raised thanks to a study made of the computerized maintenance management tool, which makes it possible to identify the steps of visits and revision of each organ of railway rolling stock. The problem is described as a noise parasite when coupling the locomotive with the Corail train because of harmonic electrical pollution that is considered to be a distortion of the sinusoidal signal and has the effects mentioned below:

Instantaneous effects: that create disturbances in the functioning of devices sensitive to harmonics, this is the case of the problem identified through the parasites detected in the speakers.

Medium and long-term effects: that cause the heating and premature aging of the electrical equipment, this advanced deterioration of the organs often generates breakdowns which obliges the railway company to replace them before the date of the change prescribed by the maintenance management tool.

Harmonic analysis and the quality of the power system is fundamental for the electric railway transport, the energy is regulated and fed to electric motors to provide traction for railway vehicles. Auxiliary power dedicated for forced ventilation of electric traction motors and passenger comfort is also regulated but can be a major source of electromagnetic noise. Because, it has many considerable and even catastrophic impact especially on the functioning of the railway signaling systems for different cases of cantonment such as European Rail Traffic Management System (ERTMS) the restricted automatic block with track circuit or axle counter [7, 8]. The resonance phenomenon can be caused by many sources such as the auxiliary static converters located in the locomotive. The $3 \mathrm{kV}$ DC power source comes from the sub-station which is composed of a step-down transformer with two secondary windings, a silicon diode rectifier and it is transmitted to the railway traction vehicle by a system of suspended flexible contact lines called catenary with an articulated device mounted on a locomotive called pantograph is brought into contact as seen in Fig.1. Once the substation feeds the locomotive through the catenary, we distinguish in the locomotive the traction power train through motors, and auxiliary for forced ventilation of motors, reactor vessels, resistances and the supply chain side of the train. The 3 phases power supply provided by the auxiliary static converter feeds the Corail train to ensure the comfort of the passengers on board such as air conditioning, heating, lighting, and sound system. That is why our study is based on the impact of the static converter of this type of locomotive E1250 on the communication quality transmitted in the sound system by analyzing the polluted harmonics power supply.

Reference [6] analyses how the railway Netherlands public transport deals with the high demand during the peak period from an environmental point of view, and how to make offpeak period more attractive than the peak for travelers through the ticket price. In Ref. [9] deals with the electromagnetic pollution in Italian railway lines by taking experimental measurements, analyzing harmonics generated by different sources such as converters located in the Uninterruptible Power Supply (UPS) and onboard the train. In Ref. [10] analyzes a proposed method to reduce $\mathrm{CO} 2$ emissions and energy costs by introducing a new solution of reactive power and compensation in order to minimize the THD. In Ref. [11] proposes how Chinese railway deals with the citizen protest against expansion of the railway high speed infrastructure because of health and environmental impacts such as noise, destruction of green areas, electromagnetic compatibility in the radiation mode. To mitigate Total Harmonic Distortion (THD) which is significant of the pollution of the threephase network supplied by the locomotive, EMC interferences study in the CM was carried out based on the impact of the auxiliary static converter of the locomotive on the sound system installed in the Corail cars. This interference causes noise in the speakers that announces permanent location information of the train which requires us to isolate the sound system to avoid noise disturbances, however passengers report their dissatisfaction with the non-functioning of the sound system. This is why experimental measures have been done to analyze the behavior of the power supply provided by the static converter $[12,13]$, it has been modeled through Matlab-Simulink with a proposed solution implemented in the output of the static converter which is the active filter chosen because of his power gain, it provides reliable operation control systems to eliminate any harmonic despite the variable amplitude of harmonic ranks due to the variable load on the Corail train side and to mitigate the harmonic distortion pollution rate that impacts the operating of the sound system and cause the premature aging of the equipment on board the train, 
while the passive filter contains passive component $\mathrm{R}, \mathrm{L}, \mathrm{C}$ and consume the energy of the signal (no power gain is available) and has resonance problems.

This paper is organized as follow: section 2 describes the locomotive E1250 under test especially the static converter located in the locomotive, as well as the sound system installed in the Corail train. Section 3 details measurements of the output power quality through voltage, current and harmonic analysis taken in a test train without passengers to analyze the electromagnetic pollution. Section 4 models the system under test from the static converter to the sound system through MatlabSimulink with and without introducing the active filter and battery compensation in order to eliminate the electric harmonic pollution. Section 5 concludes the article.

\section{Description of the locomotive E1250 and the sound system}

\subsection{Locomotive E1250}

The Moroccan railway adopts the $3 \mathrm{kV}$ Dc power supply generated by the substation to feed the traction trains. The electric locomotive under test called E1250, is a CoCo type with a power of 3900 $\mathrm{kW}$, equipped with $6 \mathrm{dc}$ motors (3 motors for each bogie) in serial mode (motor armature and inductor are traversed by the same current) with forced ventilation. The speed control system for traction motor is realized through main resistors and resistors Vernier with a change of series coupling in the 3 traction chain containing each two motors (M1-M2-M3-M4-M5-M6 in series), Parallel Series (M1-M2- M3 // M4-M5-M6), Parallel (M1-M2 / M3-M4 / M5-M6) reported in Fig. 2. The contactors are controllable through camshafts which are controlled by stepper motors, braking is achieved through: air brake, screw brake, dynamic braking. The DC motor was chosen from the outset for its characteristics perfectly adapted to railway traction:

- Very important start-up effort.

- Exceptional overload capacity.

The locomotive pulls the Corail train through the mechanical coupling and it is connected by pneumatic couplings to ensure braking continuity and control the closing system of the doors and electrical couplers $380 \mathrm{~V}$ ac ( 3 phases and Neutral cable) as shown in the figures below. The main purpose is to feed the functioning of all the operating systems in the Corail train such as the air conditioning, the lighting, the sound system ...

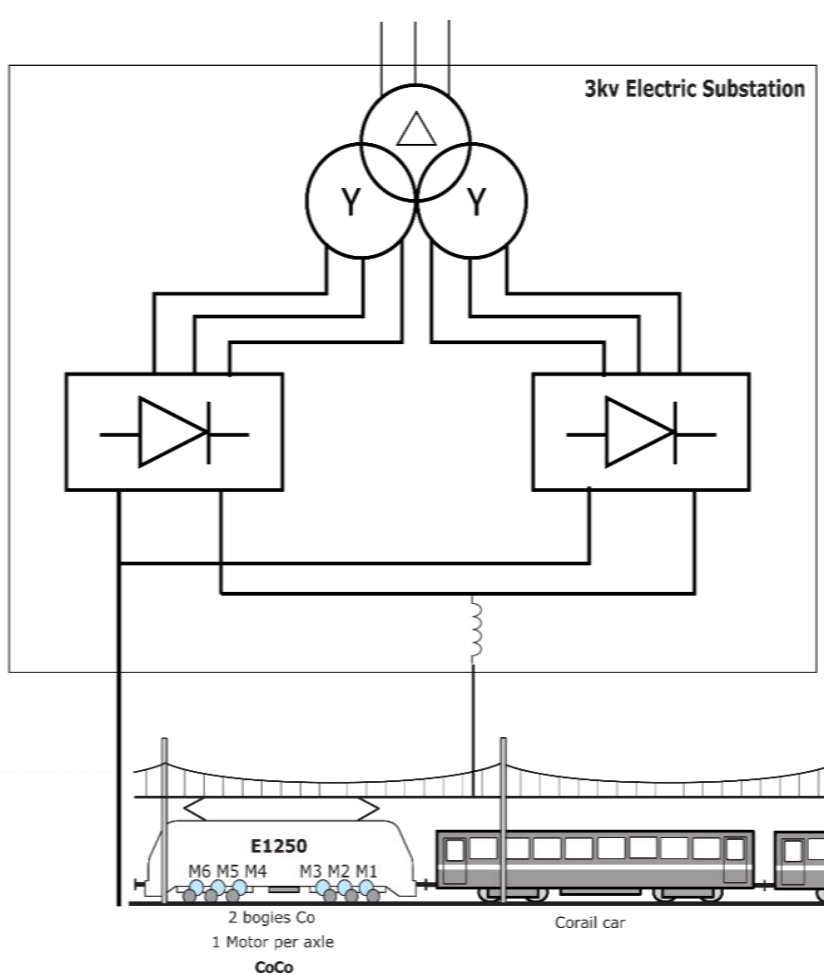

Figure. 1 The locomotive E1250 connected to Corail train

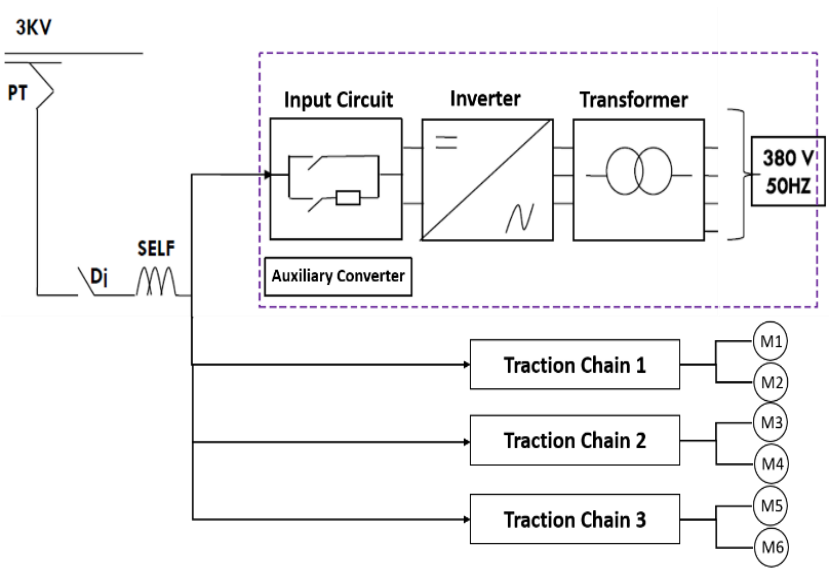

Figure. 2 Simplified electrical diagram of the locomotive

The locomotive pulls the Corail train through the mechanical coupling and it is connected by pneumatic couplings to ensure braking continuity and control the closing system of the doors and electrical couplers $380 \mathrm{~V}$ ac ( 3 phases and Neutral cable) as shown in the figures below. The main purpose is to feed the functioning of all the operating systems in the Corail train such as the air conditioning, the lighting, and the sound system.

The Figs. 3 and 4 below show the connection between the locomotive and each Corail car taking into account the electric coupler, sound coupler, and pneumatic coupler in order to guarantee the continuity of the sound line, electrical and pneumatic supply. 


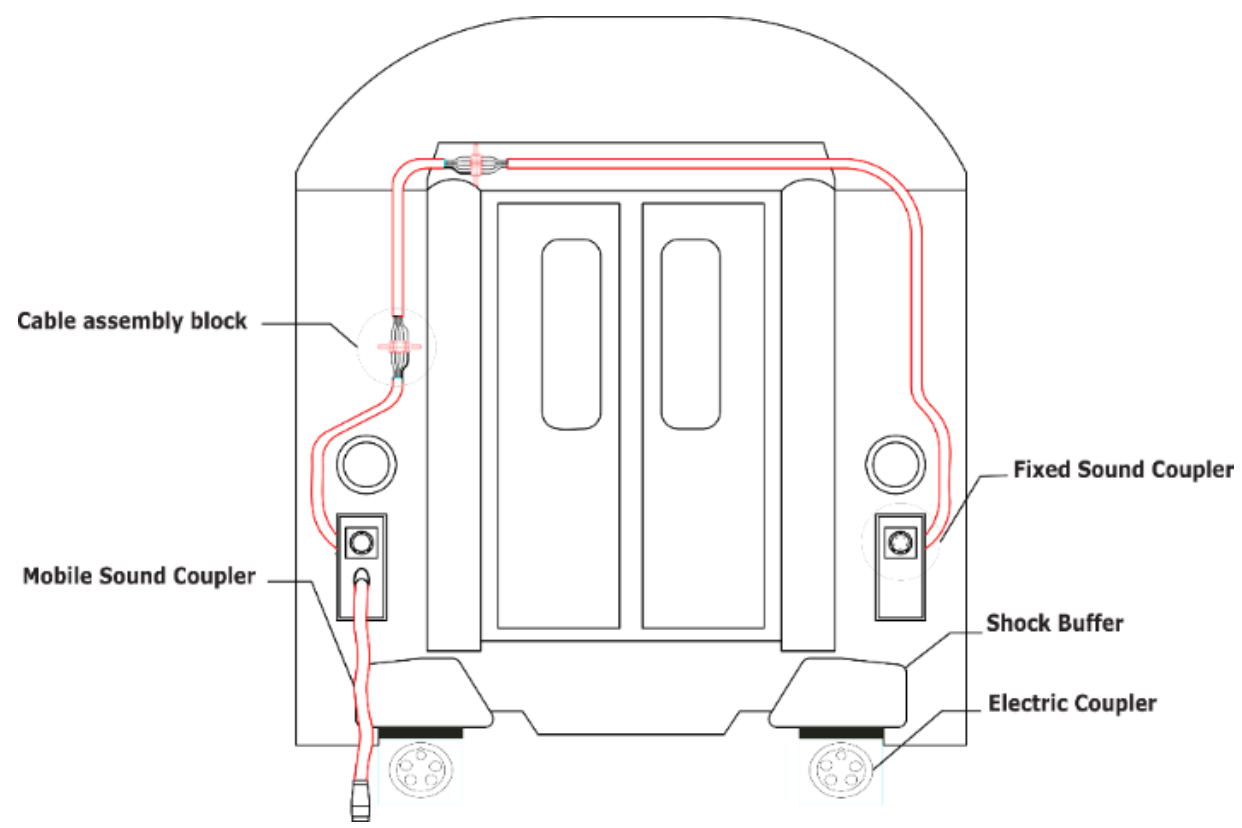

Figure. 3 Back view of the Corail car

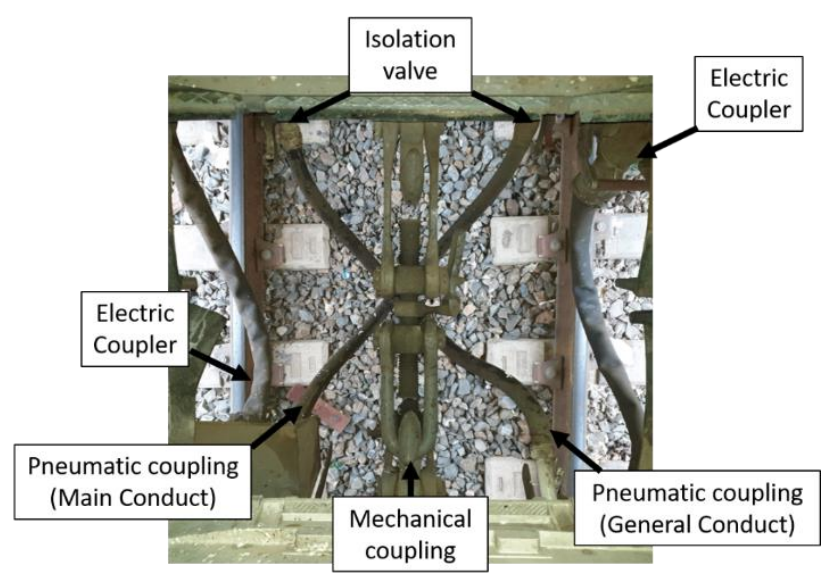

Figure. 4 Connection between the Corail cars and the locomotive

The auxiliary supply capacity through the static converters are intended for the supply of passenger cars and auxiliary groups of the locomotive (ventilation of $\mathrm{dc}$ motors, lightning, ...) and control circuits of the locomotive. The static converter under test parameters are listed in Tab. 1 and contains two outputs $380 \mathrm{~V}-50 \mathrm{~Hz}$ voltage with a capacity of $670 \mathrm{kVA}$ whose $270 \mathrm{kVA}$ are intended for the locomotive control circuit and auxiliary ventilation groups listed in the Tab 2, and the rest $400 \mathrm{kVA}$ is for the power supply of the train to ensure the comfort and safety of travelers listed in Tab 3. The $3 \mathrm{kV}$ is picked from the catenary, then lowered through the step-down chopper, then corrugated using the inverter based on thyristor, finally transformed thanks to a transformer with two secondary auxiliary and train side as shown in the Fig. 5.

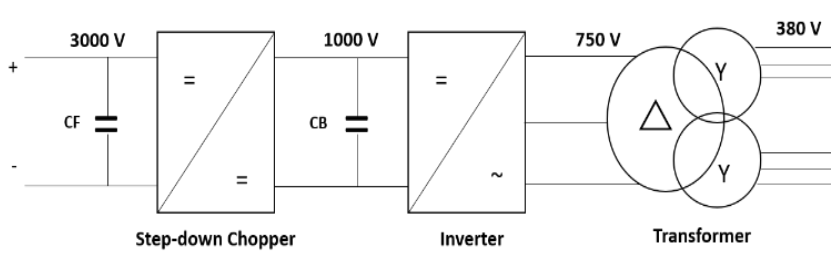

Figure. 5 Simplified diagram of the conversion chain

Table 1. Main data of the Static converter

\begin{tabular}{|c|c|c|}
\hline \multicolumn{2}{|c|}{ Main data } & Specification \\
\hline $\begin{array}{c}\text { Nominal } \\
\text { Capacity }\end{array}$ & Locomotive Side & $270 \mathrm{kVA}$ \\
\cline { 2 - 3 } $\begin{array}{c}\text { Output } \\
\text { Voltage }\end{array}$ & Corail cars Side & $400 \mathrm{kVA}$ \\
\hline $\begin{array}{c}\text { Output } \\
\text { current }\end{array}$ & Locomotive Side & $\begin{array}{c}380 / 220 \mathrm{~V} \mathrm{AC} \\
\pm 7 \%\end{array}$ \\
\cline { 2 - 3 } & Corail cars Side & $610 \mathrm{AC}$ \\
\hline \multicolumn{2}{|c|}{ Input Voltage } & $3000 \mathrm{~V}$ DC \\
\hline
\end{tabular}

Table 2. Equipment powered by static converter auxiliary side of the locomotive

\begin{tabular}{|l|c|c|}
\hline \multicolumn{1}{|c|}{ Auxiliary equipment } & alimentation & $\begin{array}{c}\text { Electric } \\
\text { power }\end{array}$ \\
\hline $\begin{array}{l}\text { Ventilator for traction } \\
\text { motor }\end{array}$ & $380 \mathrm{~V}-50 \mathrm{~Hz}$ & $30 \mathrm{KW}$ \\
\hline $\begin{array}{l}\text { Ventilator for principal } \\
\text { resistance }\end{array}$ & $380 \mathrm{~V}-50 \mathrm{~Hz}$ & $12 \mathrm{KW}$ \\
\hline $\begin{array}{l}\text { Ventilator for electrical } \\
\text { equipment }\end{array}$ & $380 \mathrm{~V}-50 \mathrm{~Hz}$ & $5,5 \mathrm{~kW}$ \\
\hline $\begin{array}{l}\text { Ventilator for static } \\
\text { converter }\end{array}$ & $380 \mathrm{~V}-50 \mathrm{~Hz}$ & $1 \mathrm{~kW}$ \\
\hline Ventilator for chopper & $380 \mathrm{~V}-50 \mathrm{~Hz}$ & $1,8 \mathrm{~kW}$ \\
\hline $\begin{array}{l}\text { Ventilator for } \\
\text { transformer }\end{array}$ & $380 \mathrm{~V}-50 \mathrm{~Hz}$ & $1,2 \mathrm{~kW}$ \\
\hline
\end{tabular}


Table 3. The systems powered by the CVS train side

\begin{tabular}{|l|c|}
\hline Systems installed for each Corail car & alimentation \\
\hline Air conditioning system & $380 \mathrm{~V}-50 \mathrm{~Hz}$ \\
\hline Lightning system & $220 \mathrm{~V}-50 \mathrm{~Hz}$ \\
\hline Sound system & $220 \mathrm{~V}-50 \mathrm{~Hz}$ \\
\hline $\begin{array}{l}\text { Automatic closing system for access } \\
\text { doors }\end{array}$ & $220 \mathrm{~V}-50 \mathrm{~Hz}$ \\
\hline Others & $220 \mathrm{~V}-50 \mathrm{~Hz}$ \\
\hline
\end{tabular}

\subsection{Sound system}

The sound system installed in the rail passenger transport equipment is very important and primordial since it announces the following information: the permanent location by selflocalization, the next stations and next stops, the destination, climate and other information, etc.

Sound system train consists of different elements starting with the GPS box capable of processing the location frames through a GPS antenna and connected to a control box that allows the processing and transfer of information announcement through an armored cable named LTS composed of 4 wires (LT1, LT2, LTM) and which is connected to an amplifier to amplify and diffuse the signal by the speakers as reported in the Fig 6.

This system installed in Corail cars was developed in our research laboratory to make the necessary tests to analyze the cause of parasite because of the feeding provided by the auxiliary static converter of the locomotive as seen in the Fig. 7.

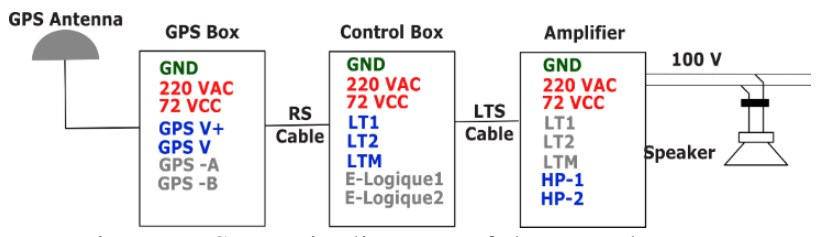

Figure. 6 Synoptic diagram of the sound system

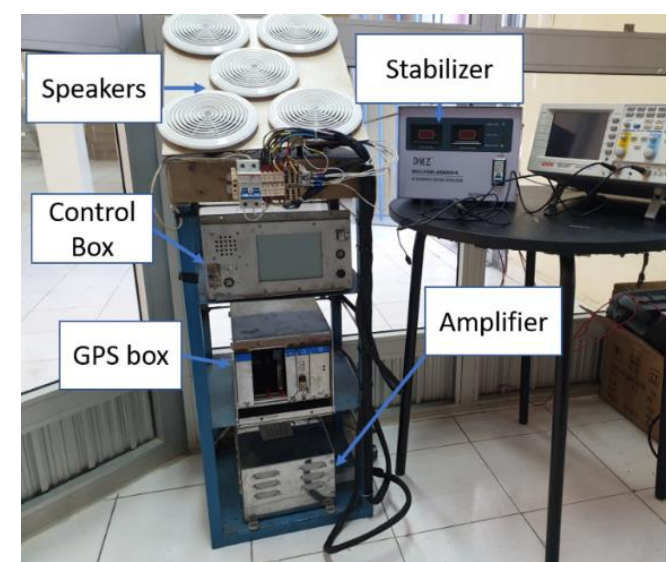

Figure. 7 The sound test bench installed for static tests in the laboratory

\section{Experimental measurements of the output voltage of the static converter}

\subsection{Measuring instruments and mode}

To experimentally investigate the power quality and electric harmonic pollution presence in the power supply generated by the locomotive [14]. Many measurements were performed on the Moroccan railway lines within two operations:

Operation 1: was dedicated for static measurements in a maintenance depot, the input and output power measurement of each organ reported in Fig. 9, 10, 11 in particular the interference observations on the sound system test bench.

- Operation 2: was dedicated for dynamic measurements reported in Fig. 12 on a track from Marrakech to Rabat which was given during the off-peak period thanks to the layout of the regulation so as not to disturb the train traffic.

The power quality and harmonics measurements provided by the locomotive at the electric coupler were made by a network analyzer capable of recording the voltage and current readings in real time. The tests were carried out by installing ammeter pincer and crocodile pincer of each phase and neutral were plugged into the analyzer as seen in the Fig. 8 and then plugged into a software recorder installed in a laptop to store all the power and energy data consumed in the path. Static and dynamic tests on a test railway track were carried in order to understand and to analyze closely the noise of the sound system and to understand the power quality supply of the static converter under test, the aim of this tests is recording the absorbed voltage and current waveform of each phase onboard the train and the output coupler.

The electric coupler reported in Fig. 8 has 4 cables including 3 phases and neutral surrounded by a non-flammable rubber sheath. It allows the continuous transmission of power between each Corail car and the locomotive as shown in the Fig. 4, the return loop is done in the last car of the train.

\subsection{Experimental results}

The purpose of measurements tests is to analyze the waveforms of the current and voltage and to identify the Resonance phenomena located in the train after connecting the locomotive under test, 


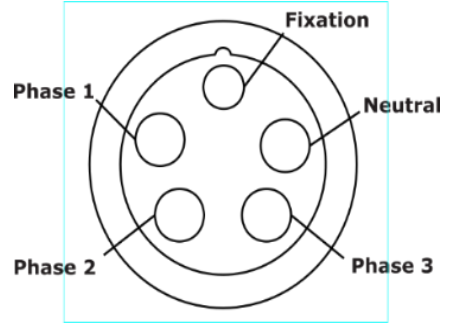

(a)

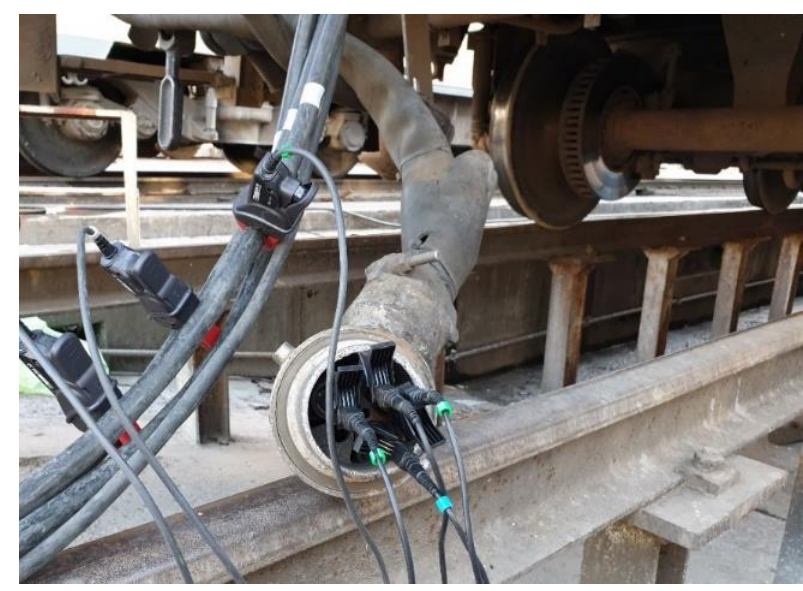

(b)

Figure. 8 (a) electric coupler view and (b) measurements taken from the electric coupler

characterized by harmonics pollution of the power supply, to the Corail train. The measurement operations were performed within two days, six hours per day and the results are reported as diagram waveforms recorded after several measurements carried out in the two operations static and dynamic survey under the same test guidelines, and the same load conditions onboard the auxiliary static converters that are the main disturbance cause in both cases running and stationary train test.

Many experimental measurements waveforms of the current and the voltage have been collected in real time and they converge towards the same results that they are not close to the fundamental sinusoidal waveform because of the electromagnetic interference injected by the static converters of the considered locomotive. The shapes of the voltage and current of the static converter of the locomotive are not perfectly sinusoidal and they are reported in Figs. 9 and 10 (phase 1, 2, 3, Neutral are represented respectively with the color black, red, blue, green). This parasite of the three-phase voltage and current shape is caused by the strong harmonics generated in the locomotives.

This irregular voltage and current waveforms prove that the power network is polluted. The harmonics generated reported in the Fig. 11 show that the ranks especially 5, 7 are very high (X-axis represent the rank of harmonic and percentage of harmonic is represented in $\mathrm{Y}$-axis). However, rank 3 is almost equal to zero because of the triangle transformer. The reasoning shows that rank 3, multiple of 3 are equal to zero and non-zero harmonic currents are therefore of rank form $6 \mathrm{k} \pm$ 1 with $\mathrm{k} \in \mathbb{N}$. The total harmonic distortion rate is equal to $21 \%$ for each phase, which is very high compared to the railway standard EN 50121, EN61000 [15-18]. This explains the reason why the sound system is parasitized during the coupling of the locomotive since it is very sensitive to the harmonics pollution generated by the common mode.

Harmonics distortion rate for each rank was measured and reported by the amplitude of each harmonic rank in Tab. 4 then the global harmonic distortion was calculated and measured through the mathematical Fourrier transform formula:

$$
T H D-I(\%)=\frac{\sqrt{\sum_{i=2}^{n} I_{n}^{2}}}{I_{1}} \times 100
$$

Influence of THD-I on the Puissance Factor/ $\cos (\phi)$ ratio:

$$
P F=\frac{\cos (\phi)}{\sqrt{1+T H D-I^{2}}}
$$

\section{Modelling the system with the proposed solution}

The consequences of the total harmonics caused by the static converter of the E1250 locomotive are:

- Premature aging or destruction of compensation capacitors.

- Phenomenon of parallel or series resonance.

- Overheating machines.

- Decrease in power factor (PF).

- Disturbance of electrical appliances (it has been noticed in the amplifier sound system).

The converter onboard the locomotive was modeled by taking into account the conversion chain parameters already reported. A theoretical study under MATLAB-SIMULINK was carried out to get closer to the reality and to see the behavior closely according to the proposed solutions by adding an active compensator and filter.

The modeled system was carried out taking into account the parameters and the real components. The result obtained for voltage, current approaches what was measured at the locomotive as seen in the Fig. 13. 


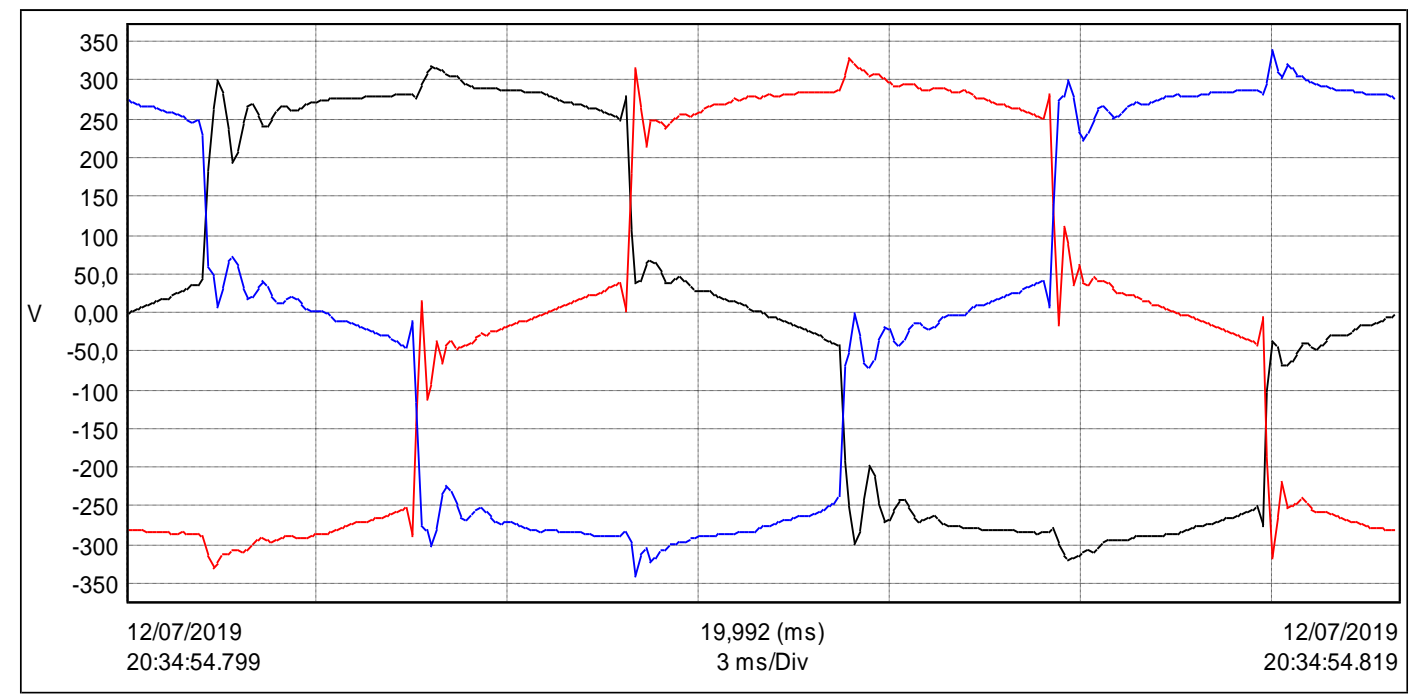

Figure. 9 Output voltage of the static converter measured in the operation 1

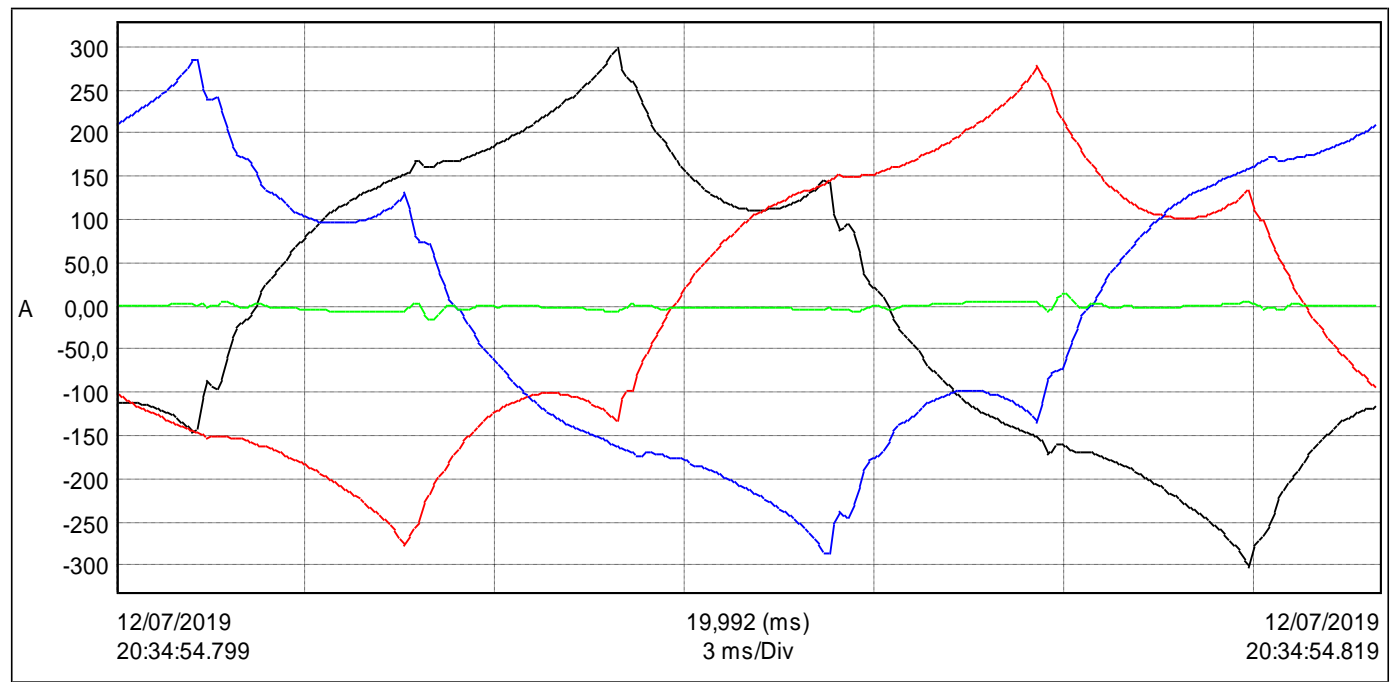

Figure. 10 Output Current of the static converter measured in the operation 1

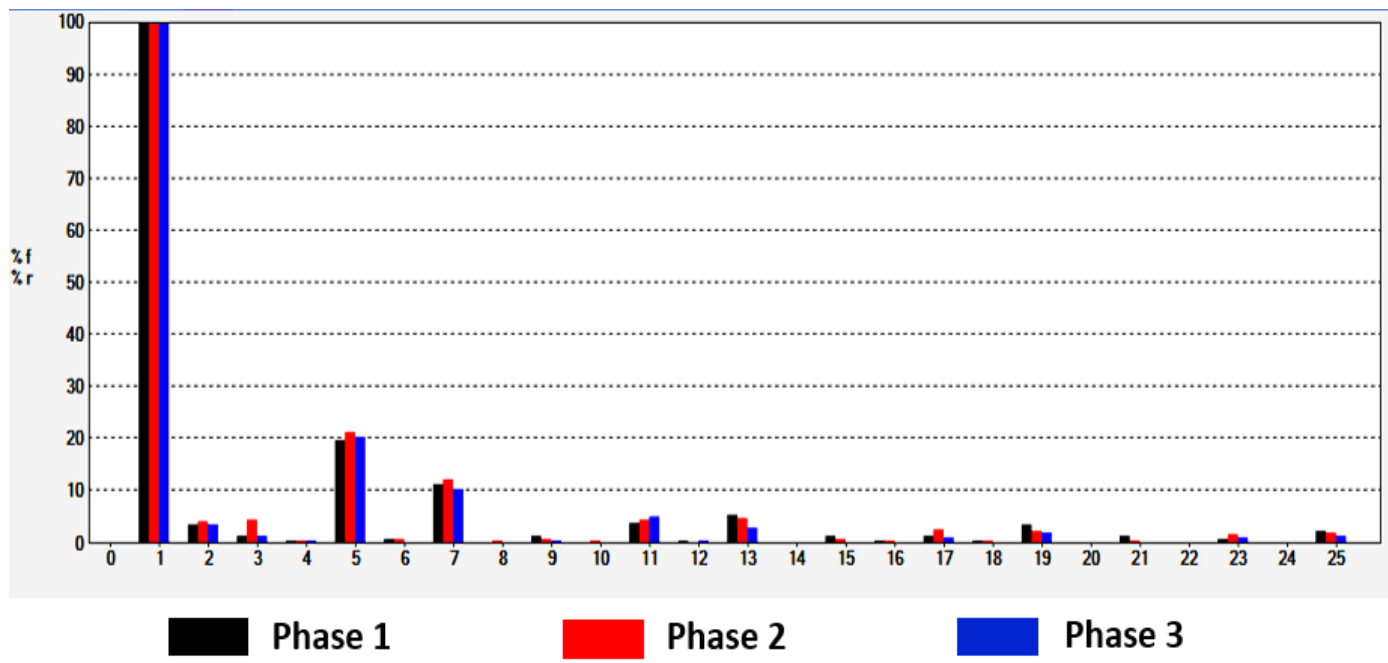

Figure. 11 Harmonic ranks of the static converter measured in the operation 1 
Table 4. Statistical analysis of the harmonic content of the static converter recorded during the measurements

\begin{tabular}{|l|l|l|l|l|}
\hline Harmonic order & Frequency $(\mathbf{H z})$ & Amplitude of Phase 1 & Amplitude of phase 2 & amplitude of phase 3 \\
\hline 1 & 50 & 235.5 & 216.7 & 224.8 \\
\hline 3 & 150 & 1.2 & 3.6 & 1.1 \\
\hline 5 & 250 & 19.8 & 22.3 & 20.2 \\
\hline 7 & 11.4 & 12.7 & 9.8 \\
\hline 9 & 450 & 1.3 & 0.6 & 0.1 \\
\hline 11 & 3.4 & 4.3 & 4.8 \\
\hline 13 & 550 & 5.2 & 4.7 & 2.8 \\
\hline 15 & 650 & 1.2 & 0.6 & 0.1 \\
\hline 17 & 1.4 & 2.2 & 0.7 \\
\hline 19 & 850 & 3.8 & 1.9 & 1.3 \\
\hline 21 & 950 & 1.2 & 0.3 & 0.0 \\
\hline 23 & 0.6 & 1.3 & 0.8 \\
\hline 25 & 1050 & 1.3 & 1.0 & 0.9 \\
\hline THD-I & 20.6 & 21.1 & 21.1 \\
\hline
\end{tabular}

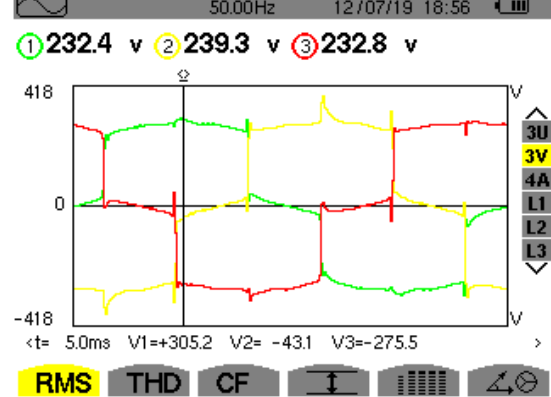

(a)

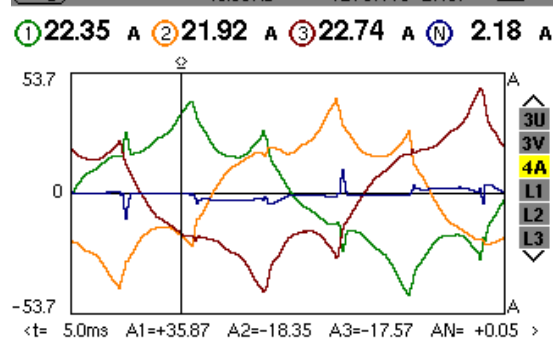

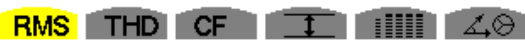

(b)

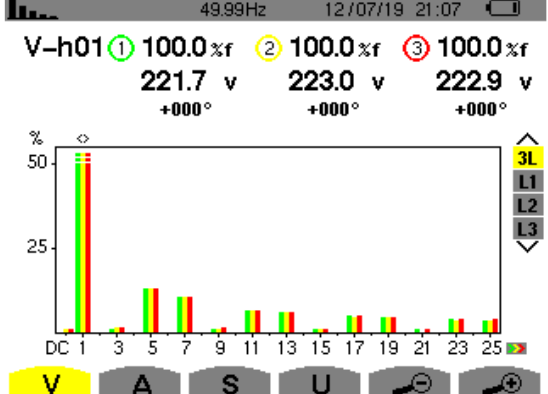

(c)

Figure. 12 (a) output voltage measured in operation 2 and (b) current measured in operation 2, and (c) harmonics analysis in operation 2

Table 5. measured powers during the tests.

\begin{tabular}{|c|c|c|c|c|c|}
\hline Power Data & Description & Phase 1 & Phase 2 & Phase 3 & Total \\
\hline P(W) & Active power & $24.54 .10^{3}$ & $23.00 .10^{3}$ & $25.05 .10^{3}$ & $72.60 .10^{3}$ \\
\hline Q (VAR) & Reactive power & $24.34 .10^{3}$ & $22.48 .10^{3}$ & $23.02 .10^{3}$ & $69.83 .10^{3}$ \\
\hline D (VAR) & Deforming power & $9.457 .10^{3}$ & $8.975 .10^{3}$ & $9.319 .10^{3}$ & $27.80 .10^{3}$ \\
\hline S (VA) & Apparent power & $35.83 .10^{3}$ & $33.39 .10^{3}$ & $35.27 .10^{3}$ & $104.5 .10^{3}$ \\
\hline PF & Puissance Factor & 0.685 & 0.689 & 0.710 & 0.695 \\
\hline $\operatorname{Cos}(\phi)$ & & 0.709 & 0.714 & 0.735 & 0.719 \\
\hline $\operatorname{Tan}(\phi)$ & & 0.996 & 0.981 & 0.923 & 0.966 \\
\hline$\phi(\mathrm{P})$ & Phase shift & $45^{\circ}$ & $44^{\circ}$ & $43^{\circ}$ & - \\
\hline
\end{tabular}
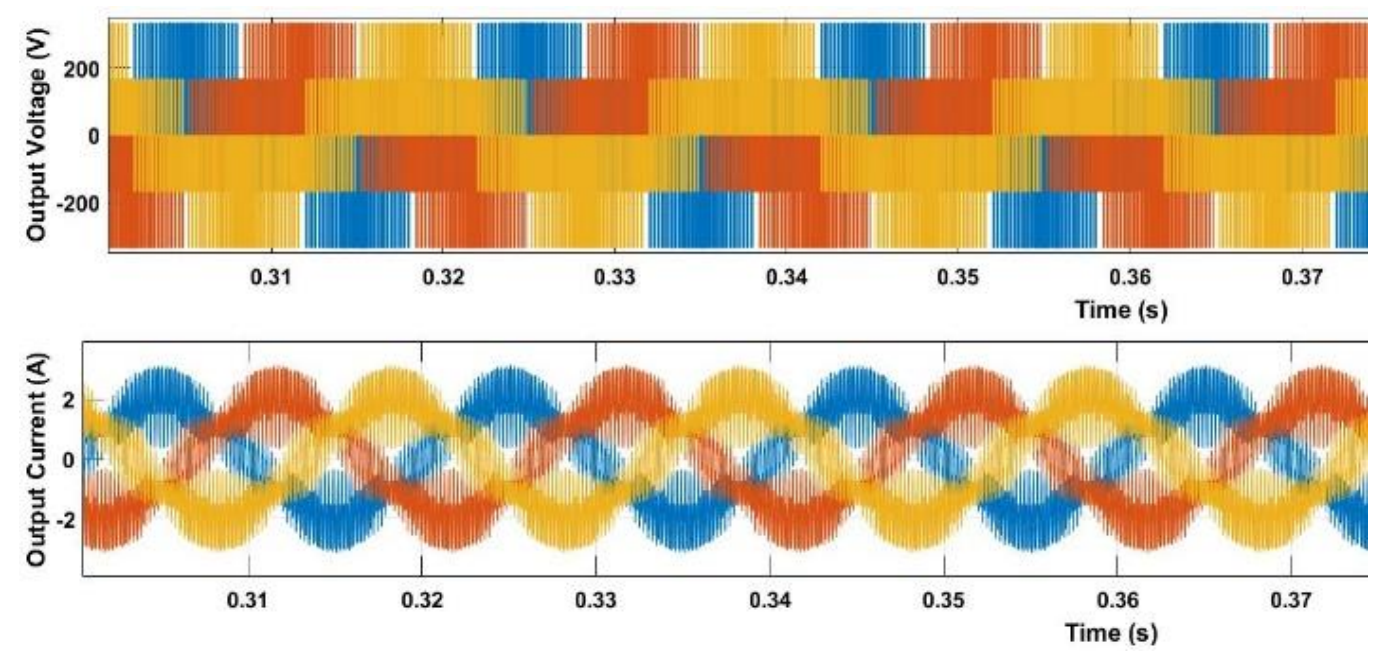

Figure. 13 Output voltage and current modeled before filtering 
The solution to mitigate the EM noise is to introduce an active filter with compensation battery. However, to implement this study that has been dimensioned, the place and weight of this component is very worrying at the locomotive. Adding to that, it requires a commissioning license that takes a long time for validation and testing. Reason why we have also decided to introduce a temporary solution while the authorization is validated by adding a stabilizer at the level of Corail cars capable of stabilizing the static converter output voltage to correct the sound situation.

The compensation capacitors installed at the output of the converter can lead to the amplification of existing harmonics. Amplification means the increase in harmonic distortion rates in voltage as in current. This amplification is due to an electrical resonance between the capacity of the battery and the line and source inductances. To compensate for reactive energy is to supply this energy in place of the distributed power network. This is why it is wise to install a capacitor bank after measuring the power reported on the Tab. 5 to improve the power factor. which can be represented in the mathematical formula:

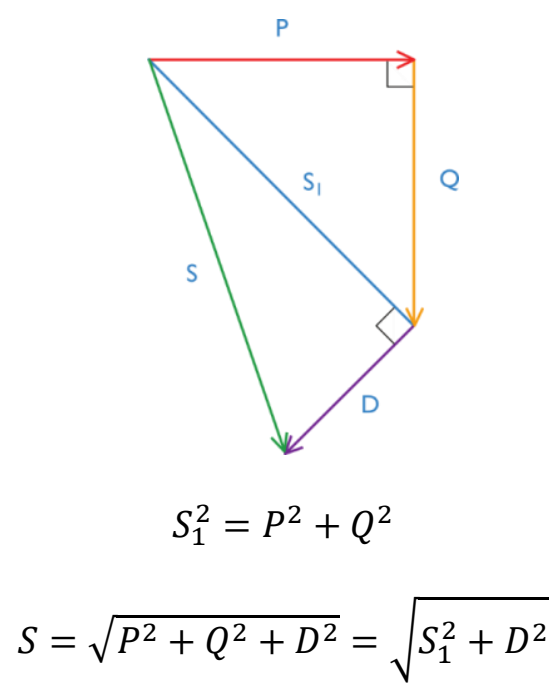

with, $Q$ : reactive power without harmonic.

The distorting power $\mathrm{D}$ has an immediate consequence on the waveform and current harmonic distortion rate. Correcting reactive power generated by harmonics will become more dangerous for reactive energy compensation equipment. Indeed, the harmonics will move the switching point and the equipment will not compensate at the desired time and will be in great demand. To eliminate the current harmonics (the distorting amps), it will be necessary to install a filtering equipment which allows in the active case, to inject a current, in phase opposition, to eliminate the harmonics seen on the supply network [19].

We can quantify the power generated by the harmonics. This power is better known Distorting Power, noted D and it is related to deforming amps. This power has an immediate consequence on the waveform and the distortion rate harmonic current. the reactive energy compensation equipment will be of no use, since it only acts on the displacement factor. Correcting a reactive power generated by the harmonics will become more dangerous for the reactive energy compensation equipment. Indeed, the harmonics will move the switching point and the equipment will not compensate at the desired time and will be more solicited. To eliminate the current harmonics (deforming amperes), it will be necessary to install a filtering equipment which allows either in the passive case, to short-circuit some rank or in the active case, to inject a current, in opposition of phase, in order to eliminate the harmonics seen on the network. The installation of these filtering equipment requires a sizing of the filter according to the distorting amps. The proposed solution shows the ultimate role of the active compensator and filter by reducing the harmonics [20]. This spectrum improvement is also accompanied by an improvement of the forms wave voltage and current as seen in the Fig.14, 15 (percentage and rank of the harmonic represent respectively the $\mathrm{Y}$-axis and $\mathrm{X}$ axis).

The advantage of the active compensator is clearly seen on the current waveform: reduction of the crest factor after correction and improvement of the power factor. The graphs show the impact of the active compensator with a very significant attenuation of THD-I. The advantages linked to this implemented solution are the following:

- Increase the active power available at the transformer secondary.

- $\quad$ Reduce in voltage drops and line losses.

- Eliminate excessive consumption of reactive energy.

\section{Conclusion}

The main purpose of this analysis is to determine the electromagnetic disturbance generated by the static converter located in the locomotive which has a negative impact on the functioning sound system. This is why experimental measurements was made to analyze the power quality and harmonics generated and. The system from the static converter to the sound system receiver was modelled and 

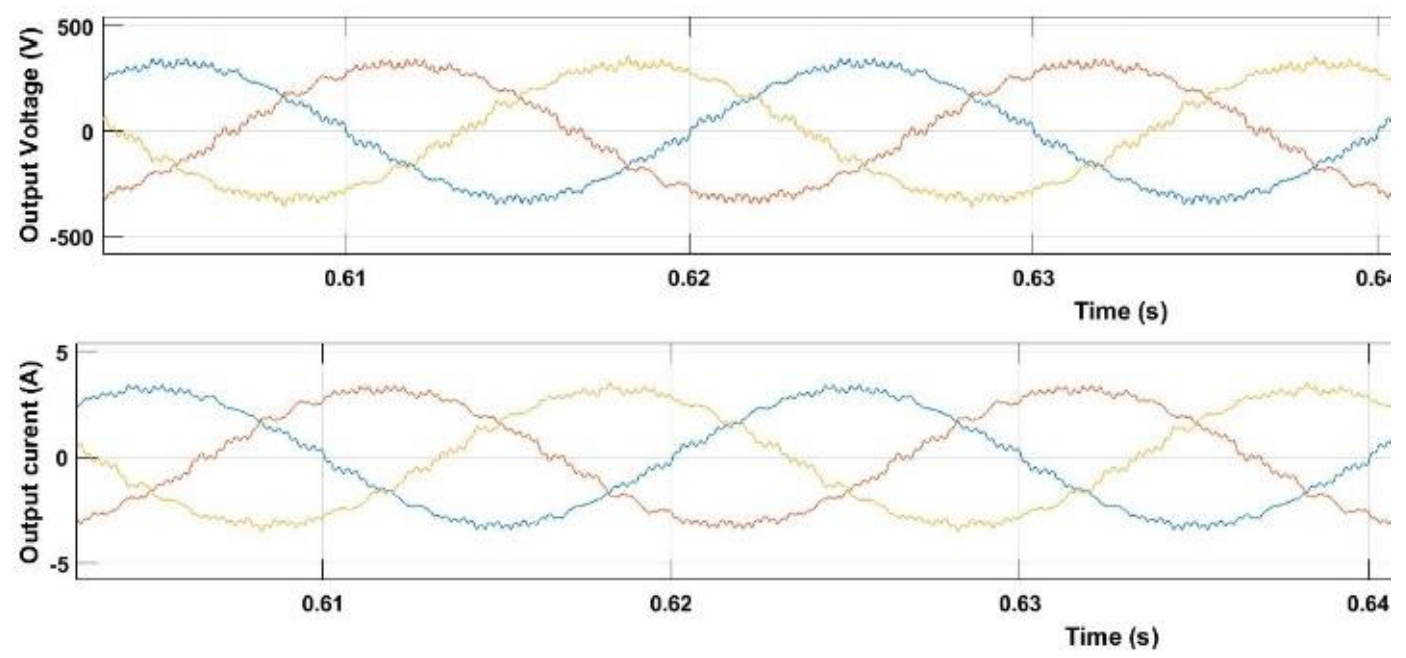

Figure. 14 Output voltage and current modelled after filtering

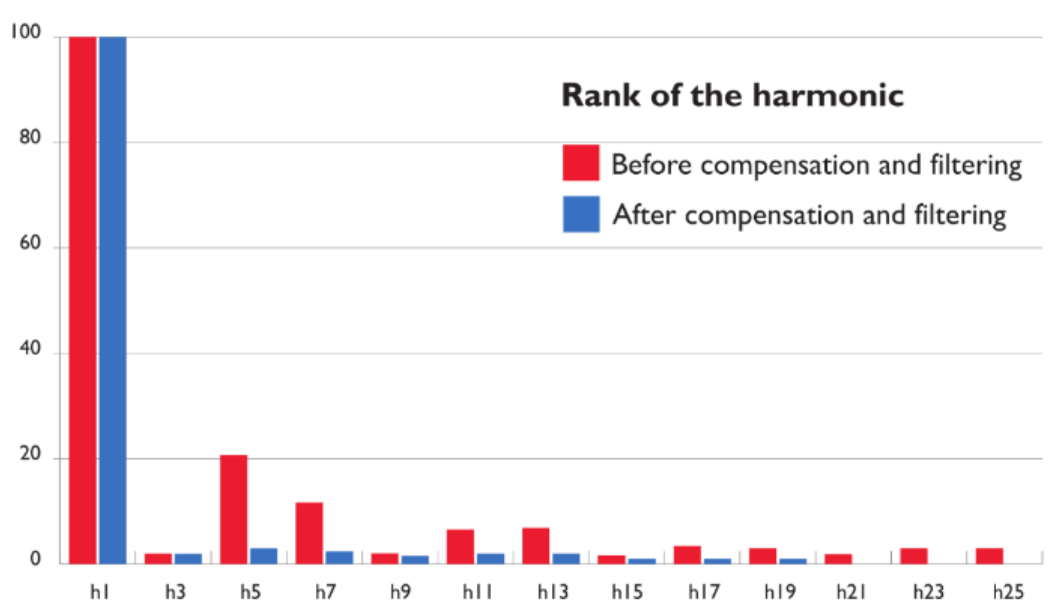

Figure. 15 Harmonic analysis before and after filtering

simulated through Matlab Simulink taking into account the command of the active filter in order to analyze the behavior of the parasites in the sound system through the speakers. The results prove that there is a remarkable improvement after the use of the proposed solution in terms of the shape of the voltage and the current, the reduction of the harmonic distortion rate, the compensation of the reactive energy.

To sum up, a sound system test bench was developed to apply different scenario with and without active filter. Until the proposed solution is implemented a stabilizer has been implemented at the entrance of each Corail car to protect the different receivers installed since another study is being put into operation taking into account the weight, space, cost and immunity and susceptibility tests of the proposed filter.

\section{References}

[1] H. Saleem, W. Jiandong, K. Zaman, E. Elsherbini Elashkar, and A. Mohamd Shoukry, "The impact of air-railways transportation, energy demand, bilateral aid flows, and population density on environmental degradation: Evidence from a panel of next-11 countries", Transportation Research Part D: Transport and Environment, Vol. 62, pp. 152168, 2018.

[2] M. Gangwar and S. M. Sharma, "Evaluating choice of traction option for a sustainable indian railways", Transportation Research Part D: Transport and Environment, Vol. 33, pp. 135-145, 2014.

[3] M. Song, G. Zhang, W. Zeng, J. Liu, and K. Fang, "Railway transportation and environmental efficiency in China", Transportation Research Part D: Transport and Environment, Vol. 48, pp. 488-498, 2016. 
[4] A. Hoffrichter, A. R. Miller, S. Hillmansen, and C. Roberts, "Well-to-wheel analysis for electric, diesel and hydrogen traction for railways", Transportation Research Part D: Transport and Environment, Vol. 17, No. 1, pp. 28-34, 2012.

[5] B. Lin, C. Liu, H. Wang, and R. Lin, "Modeling the railway network design problem: A novel approach to considering carbon emissions reduction", Transportation Research Part D: Transport and Environment, Vol. 56, pp. 95-109, 2017.

[6] P. Rietveld, "Why railway passengers are more polluting in the peak than in the off-peak; environmental effects of capacity management by railway companies under conditions of fluctuating demand", Transportation Research Part D: Transport and Environment, Vol. 7, No. 5, pp. 347-356, 2002.

[7] L. Xiaotian, Z. Haijing, Q. Bo, and H. Bochong, "EMC in Rail Transportation", Energy Procedia, Vol. 104, pp. 526-531, 2016.

[8] S. Midya and R. Thottappillil, "An overview of electromagnetic compatibility challenges in European Rail Traffic Management System", Transportation Research Part C: Emerging Technologies, Vol. 16, No. 5, pp. 515-534, 2008.

[9] M. Brenna, A. Capasso, M. C. Falvo, F. Foiadelli, R. Lamedica, and D. Zaninelli, "Investigation of resonance phenomena in high speed railway supply systems: Theoretical and experimental analysis", Electric Power Systems Research, Vol. 81, No. 10, pp. 1915-1923, 2011.

[10] L. Liudvinavicius, "Compensation of Reactive Power of AC Catenary System", Procedia Engineering, Vol. 187, pp. 185-197, 2017.

[11] G. He, A. P. J. Mol, and Y. Lu, "Public protests against the Beijing-Shenyang high-speed railway in China", Transportation Research Part D: Transport and Environment, Vol. 43, pp. 1-16, 2016.

[12] D. Serrano-Jimenez, L. Abrahamsson, S. Castano-Solis, and J. Sanz-Feito, "Electrical railway power supply systems: Current situation and future trends", International Journal of Electrical Power and Energy Systems, Vol. 92, pp. 181-192, 2017.

[13] J. Ilonciak, L. Struharnansky, and J. Kuchta, "Modular Concept of Auxiliary Converters for Diesel Electric Locomotives", Procedia Engineering, Vol. 192, pp. 359-364, 2017.

[14] S. Ronnberg and M. Bollen, "Power quality issues in the electric power system of the future", Electricity Journal, Vol. 29, No. 10, pp. 49-61, 2016.

[15] CENELEC EN 50121-4, Railway Application: Electromagnetic Compatibility, Emission and Immunity of signaling and telecommunication appliances, 2006.

[16] CENELEC EN 50121-5, Railway Application: Electromagnetic Compatibility, Part 5: Emission and immunity of railway fixed power supply installations, 2006.

[17] CENELEC EN 61000-4, Electromagnetic Compatibility : Testing and measurements techniques -5: surge immunity to conducted disturbances induced by radio frequency fields, 2007.

[18] A. Morant, A. Wisten, D. Galar, U. Kumar, and S. Niska, "Railway EMI impact on train operation and environment", In: Proc. of IEEE International Symposium on Electromagnetic Compatibility, 2012.

[19] Y. Liu, J. Xu, Z. Shuai, Y. Li, G. Cui, S. Hu and B. Xie, "Passivity-based decoupling control strategy of single-phase LCL-type VSRs for harmonics suppression in railway power systems", International Journal of Electrical Power and Energy Systems, Vol. 117, No. October 2019, p. 105698, 2020.

[20] H. Mahdinia Roudsari, S. Jamali, and A. Jalilian, "Dynamic modeling, control design and stability analysis of railway active power quality conditioner", Electric Power Systems Research, Vol. 160, pp. 71-88, 2018. 